\title{
Pathogenesis of common glomerular diseases - role of the podocyte cytoskeleton
}

\author{
This article was published in the following Dove Press journal: \\ Cell Health and Cytoskeleton \\ 8 October 2012 \\ Number of times this article has been viewed
}

\section{Takanori Kumagai \\ Flaviana Mouawad \\ Tomoko Takano}

Department of Medicine, McGill University Health Centre, Montreal, Quebec, Canada
Correspondence: Tomoko Takano Division of Nephrology, Department of Medicine, McGill University Health Centre, 3775 University Street, Room 236, Montreal, Quebec H3A2B4, Canada Tel + I $514398217 \mid$

Fax +I 5148432815

Email tomoko.takano@mcgill.ca

\begin{abstract}
Glomerulus is the filtration unit of the kidney where the first step of urine formation takes place. In the glomerulus, water and small molecules including waste products of the body are filtered into the urine, while large molecules essential for body function such as albumin are retained. When this barrier function of the kidney is impaired, protein leakage into the urine (proteinuria) occurs. Proteinuria is not only a hallmark of many glomerular diseases but also a prognostic marker of kidney disease progression. Visceral glomerular epithelial cells (commonly called podocytes) are known to have an important role in the maintenance of glomerular barrier function. In the last decade, remarkable progress has been made in podocyte biology, mainly led by the discoveries of important proteins that work together to maintain the intricate morphology and function of podocytes. Most of these so-called podocyte proteins modulate the actin cytoskeleton either directly or indirectly. The aim of the current review is to discuss the pathogenesis of common glomerular diseases with a particular focus on the role of the actin cytoskeleton in podocytes. The diseases covered include minimal change disease, focal segmental glomerulosclerosis (idiopathic and hereditary), membranous nephropathy, hypertensive glomerulosclerosis, and diabetic nephropathy.
\end{abstract}

Keywords: glomerular disease, podocyte, cytoskeleton, proteinuria

\section{Introduction to the podocyte cytoskeleton}

The nephron, the basic structural and functional unit of the kidney, consists of a glomerulus and renal tubule. The glomerulus is a network of capillary loops surrounded by the Bowman's capsule and performs the first step of blood filtering. It consists of three resident cell types: the mesangial cells, glomerular endothelial cells, and visceral epithelial cells (also known as podocytes). The podocyte, which sits on the outside of the glomerular capillary loop, consists of a large cell body, located in the urinary space, major processes, and foot processes linking the podocyte to the underlying glomerular basement membrane (GBM). ${ }^{1}$ Podocyte foot processes interdigitate with foot processes of the neighboring cell, forming between the filtration slits bridged by the glomerular slit diaphragm, which is highly permeable to water and small molecules but not to larger proteins, such as albumin. ${ }^{1,2}$ Injury to mesangial or endothelial cells often leads to inflammatory glomerular diseases (glomerulonephritis), because they are in direct contact with blood containing leukocytes, complement, and other inflammatory proteins. ${ }^{3}$ On the other hand, injury to podocytes disrupts the filtration barrier, leading to proteinuria, a hallmark of many primary glomerular diseases, such as minimal change disease, idiopathic focal segmental glomerulosclerosis (FSGS), and membranous nephropathy, or secondary glomerular diseases such as 
diabetic nephropathy. The best-characterized podocyte injury involves the reorganization of foot-process actin cytoskeleton, leading to alterations in podocyte charge or shape (effacement) and to disruption of the slit diaphragm. ${ }^{3-5}$ Thus, the spatiotemporal profile of the cytoskeleton arrangement has to be highly controlled in normal podocyte functions, and a profound understanding of the dynamics and regulation of the cytoskeleton of podocytes is essential to enable the study of glomerular diseases and eventually develop targeted therapies.

\section{Overview on structure and functions of podocytes}

In order to understand recent advances in glomerular pathogenesis, it is necessary to understand normal structure and functions of podocytes. Glomerular development is divided into four stages: renal vesicle stage, S-shaped body stage, capillary loop stage, and mature glomeruli stage. ${ }^{6}$ The progression from the S-shaped body stage to the capillary loop stage is critical for the differentiation of podocytes. ${ }^{1,2}$ During this transition, undifferentiated epithelial cells (immature podocytes) lose their mitotic activity and begin to establish their unique and complex cell architecture, marked with the appearance of foot process and the establishment of cell-cell junctions forming the slit diaphragm. ${ }^{2}$ The mature podocyte presents both epithelial features (established cell polarity with an apical and basal side) and mesenchymal features (de novo expression of vimentin, an intermediate filament protein, loss of epithelial markers such as desmosomal proteins and E-cadherin, and partial motility). ${ }^{7}$ In addition, podocytes have long been compared in analogy to smooth-muscle cells, such as capillary pericytes due to similar functional analogies, including spontaneous and angiotensin-induced contraction, as well as glucose uptake. ${ }^{8}$

A fully differentiated podocyte consists of a cell body (located in the urinary space), major processes, numerous microtubules, and foot processes branching from major processes and binding to the GBM by means of integrins and $\alpha$ - and $\beta$-dystroglycans., ${ }^{1,3}$ Podocyte foot processes are arranged in a characteristic interdigitating pattern with foot processes of neighboring podocytes, thereby forming the filtration slits that are bridged by the slit diaphragm, a modified adherens junction. ${ }^{1,2,9}$ Foot-process cytoskeleton consists of highly organized parallel and contractile actin-filament bundles. The dynamic regulation of the latter organization is crucial for the proper function of podocytes. Three distinct membrane domains functionally define foot process: the apical membrane domain, the slit diaphragm, and the basal membrane domain, all of which contain specialized proteins responsible for the dynamic regulation of podocytes. ${ }^{2,4}$ These three domains are linked to each other and to the contractile apparatus: the actin skeleton. ${ }^{2}$ Any disruption in the expression or function of these domains and their specialized proteins leads to actin rearrangement and loss of foot-process architecture, known as foot-process effacement, marked with proteinuria (please refer to Table 1 for more details). ${ }^{2,5}$

Under normal physiological conditions, podocyte functions can be classified as described in the following sections.

\section{The podocyte: a mechanosensing contractile cell in the glomerulus}

As described earlier, podocytes show unique microtubuleand actin-rich architecture with an intermediate phenotype between epithelial and mesenchymal cells showing analogy with smooth-muscle cells, particularly capillary pericytes. ${ }^{8}$ These features enable podocytes to contract in response to upstream mechanical signals, potentially controlling blood flow, in addition to the historically known mesangial cells. ${ }^{8,10}$ Moreover, when mouse podocytes were subject to fluid shear stress, to mimic the flow of glomerular ultrafiltration, tyrosine kinases and Rho kinases were activated, leading to actin reorganization in order to withstand the fluid shear stress. ${ }^{11}$ The findings clearly indicate that podocytes serve as mechanosensing cells to sustain the normal capillary structure and barrier function. ${ }^{10-12}$

\section{Regulation of glomerular fluid flux across the glomerular barrier}

It has been long recognized that the slit diaphragm, which connects adjacent foot processes, is essential in blocking the leakage of large molecules (eg, protein) into the urine. However, it was not known how this physical barrier could escape from "clogging" with large molecules. The identification of a subpodocyte space using serial transmission microscopy in 2007 shed some light on this issue. ${ }^{13}$ Subpodocyte space consists of the restricted area bound by the podocyte cell body and its major processes, covering $60 \%$ of the entire GBM. ${ }^{13}$ Using isolated, perfused glomerulus and an in vivo multiphoton imaging technique, Salmon et al showed that in these areas of subpodocyte space, proteins were washed out. ${ }^{14}$ One hypothesis of this reverse filtration (flushing back) is the constant movement of the podocyte along the GBM. ${ }^{7}$ Although some studies suggest that detectable movement of podocytes in vitro and in vivo occur, ${ }^{15}$ direct and solid evidence still needs to be provided. Endocytosis is another mechanism by which 


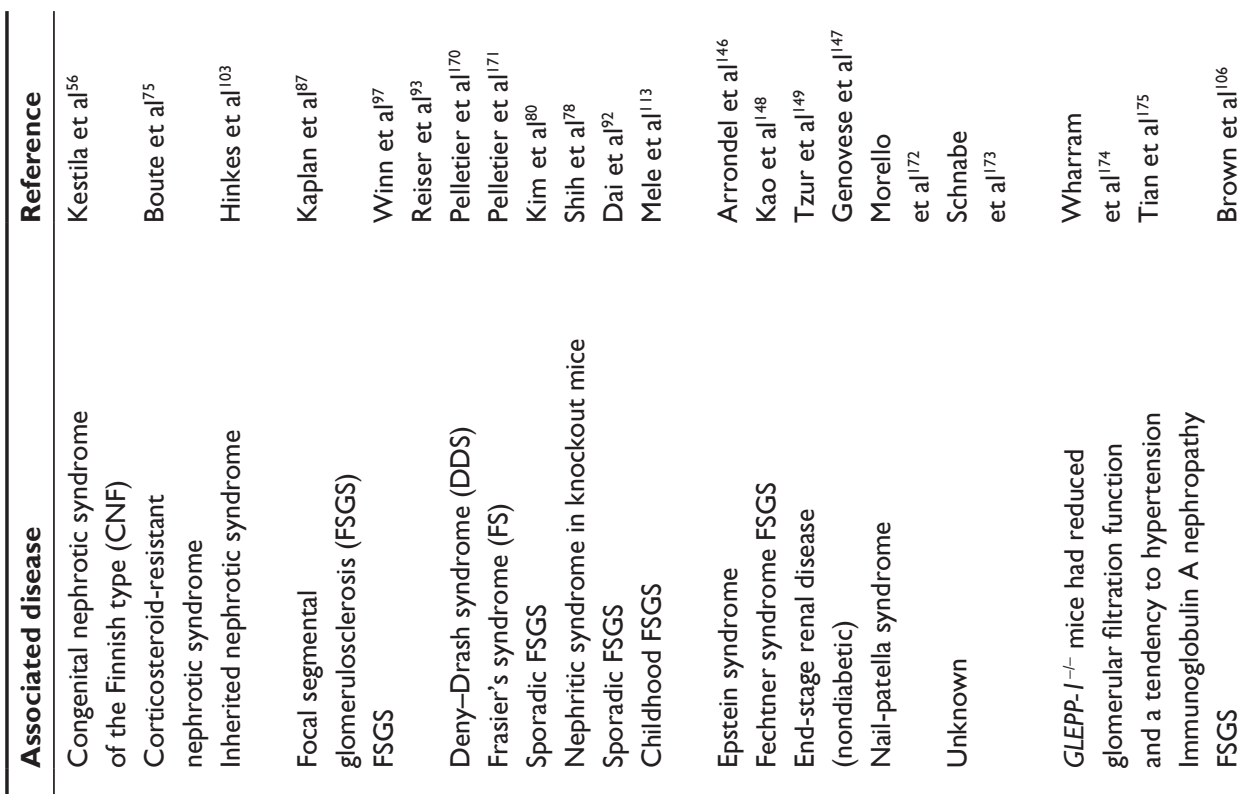


podocytes prevent filter clog. ${ }^{16}$ Disappearance of aggregates residing on the GBM due to sequential intravenous injections of protamine and heparin into rats was shown to be due to podocyte phagocytosis. ${ }^{16}$ More recently, albumin endocytosis was described in conditionally immortalized mouse and human podocytes in a statin-sensitive manner. ${ }^{17}$ New evidence suggests the existence of an active transport mechanism (neonatal Fc receptor, an immunoglobulin-G and albumin receptor) in the podocyte to remove immunoglobulins accumulated at the filtration barrier. ${ }^{18}$

\section{Regulation of the GBM itself}

GBM is mainly composed of polymers of laminin and type IV collagen. ${ }^{19}$ This composition changes temporally during glomerular development. ${ }^{20}$ Initially, both endothelial cells and podocytes produce laminin $\alpha 1 \beta 1$, and later during development, laminin replacement occurs resulting in the production of laminin $\alpha 5 \beta 2$ by the same cells. ${ }^{21}$ The collagen $\alpha 1 \alpha 2 \alpha 1$ (IV) network is first produced by the endothelial cells during fetal development. ${ }^{20}$ This network is then replaced by the $\alpha 3 \alpha 4 \alpha 5$ network produced solely by the podocyte. ${ }^{19}$ Absence of this network results in several kidney disorders, such as Alport syndrome. ${ }^{19}$ The mechanism and reason for the GBM composition isoform switch during development are still unknown, but this may be important for the maintenance and achievement of the differentiated states of podocytes.

\section{Importance of cross talk between podocytes and adjacent cells}

A detailed description of podocytes in isolation can only provide information of their individual biology. In order to evaluate the contribution of the podocyte to the physiology of the entire glomerulus, we should recognize the interactions of the podocyte with its adjacent cells. ${ }^{22}$ Podocyte-specific knockout systems have identified the role of podocytes in maintaining healthy fenestrated endothelium by the production of vascular endothelial growth factor (VEGF) acting on VEGF receptors on the endothelial cells. ${ }^{23}$ Interaction between podocytes and mesangial cells is also important, especially when we consider glomerular injury. Chemokines produced by either podocytes or mesangial cells can interact with their respective receptor on these same cells and influence their local migration and adherence to the GBM. ${ }^{24,25}$

\section{Immunological functions of podocytes}

The emerging immunological role of podocytes has recently been getting more attention. Cultured podocytes express
Toll-like receptor 4 (TLR4) on their surface, which upon stimulation result in a marked induction of chemokines. ${ }^{26}$ In addition, it has been shown that in response to the binding of lipopolysaccharides to TLR4, podocytes start expressing on their surface B7-1 (T-cell costimulatory molecule involved in antigen processing), which led to actin cytoskeleton rearrangement and slit-diaphragm reorganization, resulting in proteinuria. ${ }^{27}$ Thus, podocytes may play a role in innate immunity, in the surveillance for pathogens, and initiation of danger signalling in the Bowman's space.

\section{Common glomerular diseases associated with podocytes}

Many proteinuric kidney diseases are associated with cytoskeletal derangement of podocytes accompanied by defective permselectivity. Diseases characterized by heavy proteinuria $(>3.5 \mathrm{~g} /$ day $)$ and hypoalbuminemia $(<3.0 \mathrm{~g} / \mathrm{dL})$ are collectively called "nephrotic syndrome." In this review, we will focus on selected proteinuric glomerular diseases for which recent studies have revealed some new insights into the pathomechanisms, including minimal-change diseases, FSGS (idiopathic and familial), HIV-associated nephropathy (HIVAN), membranous nephropathy(MN), hypertensive nephrosclerosis, and diabetic nephropathy.

\section{Minimal-change disease}

Minimal-change disease is a major cause of nephrotic syndrome in children and is also commonly seen in adults. ${ }^{28}$ A sudden onset of heavy proteinuria and edema is the characteristic feature of the disease. The main treatment for minimal-change disease is corticosteroid, with a generally good response. ${ }^{28}$ However, recurrence is frequent and steroid dependence or resistance can occur. In such cases, cytotoxic drugs such as cyclophosphamide can then be used. ${ }^{28}$ To date, the cause of minimal-change disease remains unknown. However, it was reported that a donor kidney from a patient with minimal-change disease functioned normally in the recipient, suggesting that a humoral factor is responsible for the disease. ${ }^{29}$ Measles and Hodgkin's disease are known to trigger minimal-change disease, suggesting a pathological role of $\mathrm{T}$ lymphocytes, a notion also supported by the effectiveness of corticosteroid. ${ }^{30}$ In line with this clinical evidence, T-cell hybridomas derived from $\mathrm{T}$ cells from a patient with minimal-change disease were shown to induce significant proteinuria when injected into rats. ${ }^{31}$ Although the identity of the permeability factor has not been confirmed, Th2-derived cytokines - in particular, interleukin-13 (IL-13) and angiopoietin-like $4-$ are the current main candidates. ${ }^{32}$ 
IL-13 was increased in T cells from patients with relapsed minimal-change disease, compared with those in remission. ${ }^{33}$ IL-13 transgenic rats showed pathological features similar to minimal-change disease in humans.$^{34}$ Expression of nephrin and podocin was reduced in IL-13 transgenic rats, suggesting that signaling downstream of these proteins may be disturbed (refer to the paragraphs "Nephrin" and "Podocin" of the section "Familial FSGS"). ${ }^{34}$ More recently, a secreted glycoprotein, angiopoietin-like-4, was identified as a possible permeability factor in minimal change disease. ${ }^{35}$ Overexpression of angiopoietin-like 4 in rat podocytes but not in adipose tissue led to heavy proteinuria, loss of the GBM negative charge, and foot-process effacement. ${ }^{35}$ It was proposed that hyposialylated angiopoietin-like 4 was responsible for these changes, and when transgenic rats overexpressing angiopoietin-like 4 were treated with a sialic acid precursor, $N$-acetylD-mannosamine, sialylation of glomerular angiopoietin-like 4 increased and albuminuria was ameliorated. ${ }^{35}$ It is unclear whether angiopoietin-like 4 is a circulating humoral factor or acts locally, and the role of hyposialylated angiopoietinlike 4 in minimal-change disease in humans is yet to be determined. In addition to a humoral factor, a recent study demonstrated an increased level of B7.1 (CD80) in podocytes in active minimal-change disease but not in FSGS. ${ }^{36}$ Podocyte B7.1 activation through TLR3 and 4 caused actin rearrangement of podocytes, leading to proteinuria and foot-process effacement. ${ }^{27,37}$ While IL-13, angiopoietin-like 4, and B7.1 were shown to induce foot-process effacement in vivo, how they modulate the cytoskeletal components of podocytes (microtubules and actin) has not been reported.

\section{Focal segmental glomerulosclerosis}

FSGS is a pathological diagnosis highlighting the focal (some but not all glomeruli are affected) and segmental (only a part, not the entire glomerulus, is affected) nature of glomerulosclerosis. The incidence of FSGS appears to be increasing, constituting $\sim 20 \%$ and $\sim 40 \%$ of nephrotic syndrome in children and adults, respectively. ${ }^{38}$ In the United States, FSGS is currently the most common primary glomerular disease causing end-stage renal disease. ${ }^{39}$ Classification of FSGS is complex, with some degree of overlap between different categories. FSGS can be generally divided into two main groups: idiopathic form and secondary form. ${ }^{39}$ A number of hereditary (familial) forms of FSGS discovered in the last 14 years can be included in the latter ${ }^{39}$ but form a distinct group. Idiopathic FSGS is believed to be caused by a humoral factor. ${ }^{40}$ It typically presents with symptoms of nephrotic syndrome, but is generally more treatment-resistant, compared with minimal-change disease. Secondary forms have specific causes, such as genetic mutations, ${ }^{41}$ virus (particularly HIV), ${ }^{42}$ drugs (eg, heroin, ${ }^{43}$ interferon ${ }^{44}$ ), and obesity. ${ }^{45}$ Secondary forms typically present with nonnephrotic proteinuria and often impaired renal function. ${ }^{46}$ In the current review, we will briefly discuss idiopathic and familial FSGS as well as HIV-associated nephropathy, focusing on the implication of the cytoskeleton. Additionally, the readers are referred to excellent reviews for more details. ${ }^{39,41,47}$

\section{Idiopathic FSGS}

Since the landmark paper by Savin et al, it is widely accepted that idiopathic FSGS is caused by a circulating permeability factor. ${ }^{40}$ Observations that support this hypothesis include the improvement of proteinuria by immunoadsorption, and the rapidity and high incidence of disease recurrence after renal transplantation. ${ }^{48}$ To date, several candidates of circulating permeability factor have been proposed, including cardiotrophin-like cytokine 1 $(\mathrm{CLC}-1)^{48}$ and soluble urokinase receptor (suPAR). ${ }^{49}$

The permeability factor in FSGS has a strong affinity for galactose. ${ }^{50} \mathrm{CLC}-1$ was identified by galactose affinity chromatography followed by mass spectrometry. ${ }^{48}$ CLC-1 is a member of the IL-6 family, and its serum level is increased up to 100-fold in patients with recurrent FSGS in comparison to healthy controls. ${ }^{48}$ CLC-1 decreases nephrin expression in glomeruli and cultured podocytes, and a monoclonal antibody to CLC-1 blocks the albumin-permeability effect of active FSGS sera. ${ }^{48}$ However, detailed effects of CLC-1 on the cytoskeleton have not been reported.

Wei et al proposed that suPAR could be a permeability factor for FSGS. ${ }^{49}$ The serum level of suPAR was significantly higher in patients with FSGS as compared with patients with other types of proteinuric disease or healthy subjects, and the higher pretransplant suPAR level was correlated with posttransplant recurrence of the disease. ${ }^{49}$ Mice overexpressing suPAR developed albuminuria, footprocess effacement, and mesangial expansion. ${ }^{49}$ Interestingly, suPAR activated $\beta 3$ integrin in podocytes both in vivo and in vitro. ${ }^{49} \beta 3$ integrin plays an important role both in anchoring podocytes to the glomerular basement membrane and in the development of mature foot processes..$^{51,52}$ The urokinase receptor $\beta 3$ signaling pathway has been shown in tumor cells to involve the p130Cas-Crk complex, DOCK180, and Rac, leading to actin polymerization, cell-membrane protrusion, and cell motility. ${ }^{53}$ Thus, suPAR is an attractive candidate for a permeability factor, which is likely to cause actin reorganization via $\beta 3$ integrin. Of note, elevated levels of suPAR were also reported in a small pool of patients with secondary 
forms of FSGS and minimal-change disease. ${ }^{54}$ However, the patient characterization may not have been adequate, and the number of studied patients was small, so no firm conclusion could be drawn from the study. ${ }^{55}$ Whether suPAR is a permeability factor in idiopathic FSGS is yet to be validated, and the cellular source and mechanism of production of suPAR in patients with idiopathic FSGS remains to be elucidated.

\section{Familial FSGS}

Over the last decade, a number of gene mutations responsible for familial FSGS have been discovered. Although the incidents of each mutation could be small, much has been learned regarding the cytoskeletal regulation of podocytes from these gene mutations, since most of the affected genes are involved in the regulation of the actin cytoskeleton. We will briefly describe each gene, focusing on its impact on the cytoskeleton. For more details, readers are referred to excellent reviews. ${ }^{39,41}$ The main structural elements of podocyte and the slit diaphragm are illustrated in Figure 1.

\section{Nephrin}

Nephrin was initially discovered as a gene whose mutations cause congenital nephrotic syndrome of the Finnish type. ${ }^{56}$
In addition, nephrin mutations have been identified in children with steroid-resistant nephrotic syndrome ${ }^{57}$ and in one patient with adult-onset FSGS. ${ }^{58}$ Nephrin is a transmembrane protein and is a structural backbone of the slit diaphragm. Moreover, its cytoplasmic domain acts as the signaling center for actin cytoskeletal regulation., ${ }^{2,59}$ Upon tyrosine phosphorylation, nephrin recruits the adaptor protein Nck and promotes actin polymerization. ${ }^{60-62}$ Phosphoinositide-3 kinase ${ }^{63}$ and the adaptor molecule $\mathrm{Crk}^{64}$ are also recruited to nephrin in a tyrosine phosphorylation-dependent manner. Nephrin also interacts directly with $\alpha$-actinin $4^{65}$ and the $\alpha$-actinin-binding protein MAGUK with inverted domain structure (MAGI)-1 ${ }^{66}$ and MAGI-2, ${ }^{65}$ adaptor molecules that also bind to synaptopodin. ${ }^{67}$ MAGI-1 links the actin cytoskeleton to junctional adhesion molecule 4, another slit-diaphragm protein, but the function of this interaction remains to be elucidated. ${ }^{66}$

\section{Podocin}

Podocin, a member of the stomatin protein family, is exclusively expressed in podocytes. Podocin associates with lipid rafts, and recruits nephrin and CD2-associated protein (CD2AP) to the appropriate location in the slit

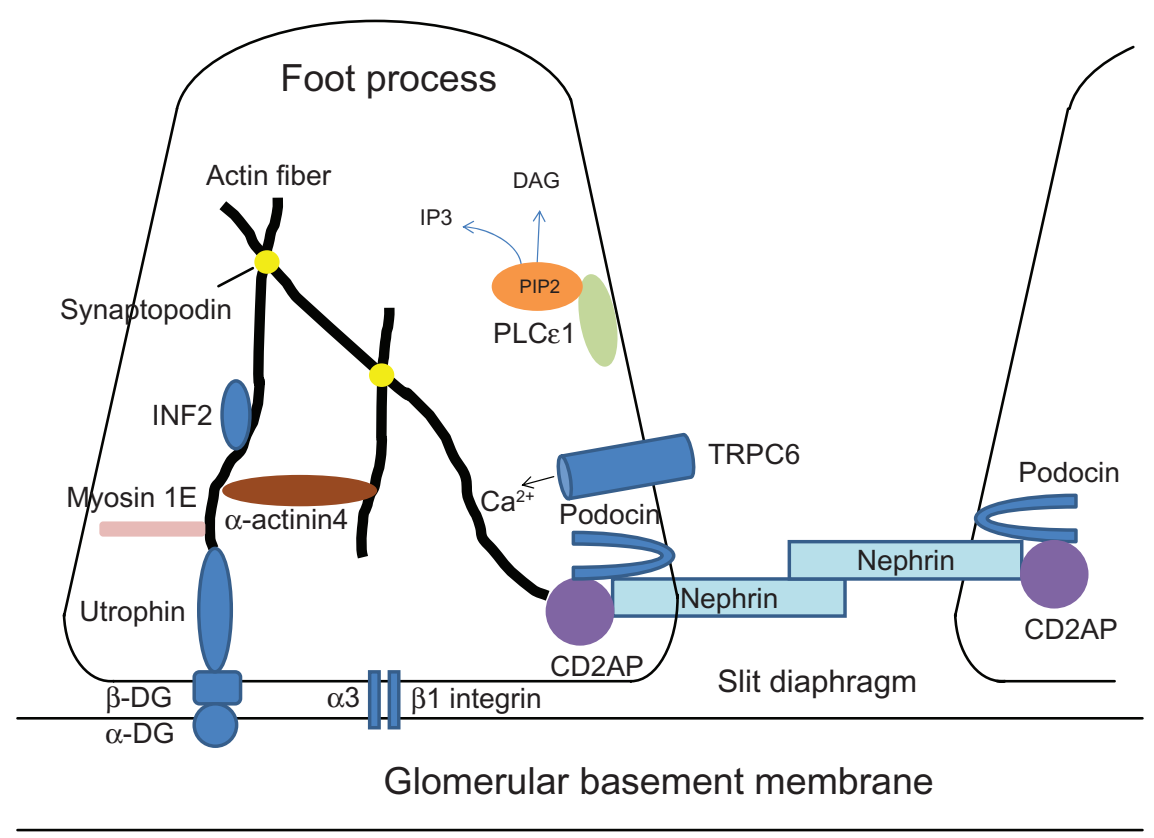

Figure I The components of the foot process and the slit diaphragm.

Notes: Nephrin interacts with podocin, a transmembrane hairpin-like scaffolding protein and with CD2AP, an adapter protein. The nephrin complex induces actin polymerization. The actin cytoskeleton is stabilized by $\alpha$-actinin-4, synaptopodin, INF2, and myosin IE, and linked to the slit diaphragm through CD2AP. PLCEI catalyzes the hydrolysis of phosphatidylinositol-4,5-bisphosphate $\left(\mathrm{PIP}_{2}\right)$ and generates the second messengers inositol I,4,5-triphosphate $\left(\mathrm{IP}_{3}\right)$ and diacylglycerol $(\mathrm{DAG})$. IP $\mathrm{P}_{3}$ releases $\mathrm{Ca}^{2+}$ from the endoplasmic reticulum. The concentration of $\mathrm{Ca}^{2+}$ in the cytoplasm regulates actin polymerization. Transient receptor potential canonical (TRPC) 6 is a Ca ${ }^{2+}$ ion channel and has a role as a sensor of mechanically induced membrane stretch by translating mechanical tension to ion-channel action. The foot processes are anchored to glomerular basement membrane through integrins (predominantly $\alpha 3 \beta$ I integrin) and $\alpha$ - and $\beta$-dystroglycans (DGs). Almost all the mutations of familial focal segmental glomerulosclerosis are slit-diaphragm components and/or the regulators of the actin cytoskeleton.

Abbreviation: INF2, inverted formin 2. 
diaphragm, ensuring a stable and proper functioning filtration barrier. ${ }^{68}$ The closest homologue of podocin is MEC-2 in Caenorhabditis elegans. Interestingly, MEC-2 is part of a multiprotein channel complex that transduces the sensation of gentle touch. ${ }^{69}$ In addition, a recent study ${ }^{70}$ demonstrated the interaction between podocin and transient receptor potential canonical (TRPC) 6, which is activated by membrane stretch. ${ }^{71}$ An intriguing hypothesis that the podocin-TRPC6 complex functions as a mechanosensor at the slit diaphragm has been proposed. ${ }^{72,73}$ Podocin-knockout mice develop proteinuria and severe mesangial sclerosis and die a few days after birth. ${ }^{74}$ Besides the absence of podocin, no nephrin was found in the slit diaphragm of podocin-knockout mice, ${ }^{74}$ further supporting the role of podocin in recruiting nephrin to the slit diaphragm. Although mutations of podocin cause autosomal recessive, early onset, childhood FSGS, ${ }^{75}$ it has been shown that these mutations can be found in sporadic cases of adult-onset FSGS as well. ${ }^{76,77}$

\section{CD2-associated protein}

CD2AP is an $80-\mathrm{kDa}$ protein that is critical for stabilizing contacts between $\mathrm{T}$ cells and antigen-presenting cells. ${ }^{78}$ Its role in podocytes was discovered when knockout mice showed congenital nephrotic syndrome and died at 6-7 weeks of age from renal failure. ${ }^{78}$ In addition, compound heterozygosity for CD2AP and synaptopodin results in proteinuria and FSGS-like glomerular damage in mice. ${ }^{79} \mathrm{CD} 2 \mathrm{AP}$ mutations were found in patients with FSGS.$^{80} \mathrm{~A}$ homozygous mutation in CD2AP was found in a 10-month-old patient with FSGS, ${ }^{81}$ and three unrelated cases bearing heterozygous mutations in CD2AP were reported. ${ }^{82} \mathrm{~A}$ recent study revealed that $\mathrm{CD} 2 \mathrm{AP}$ regulates the expression of cytosolic cathepsin L, thereby maintaining organization of the podocyte actin cytoskeleton. ${ }^{83}$

\section{$\alpha-A c t i n i n ~ 4$}

$\alpha$-Actinin-4 is an actin-bundling protein. ${ }^{84}$ Lymphocytes from homozygous $\alpha$-actinin 4 -deficient mice showed increased chemotaxis, suggesting a role of $\alpha$-actinin 4 in cell migration. ${ }^{84}$ In addition, podocytes derived from $\alpha$-actinin 4 -deficient mice were less adherent to the GBM components collagen IV and laminin-10 and 11, suggesting its role in maintaining the podocyte-GBM interaction via integrins. ${ }^{85,86}$ The role of $\alpha$-actinin 4 in human kidney disease was first recognized when mutations of $\alpha$-actinin 4 were found in autosomal dominant/adult-onset FSGS. ${ }^{87,88}$ To date, five mutations (W59R, I149del, K255E, T259I, S262P) have been reported. ${ }^{87,88}$ These five mutants bind to F-actin with a higher affinity than the wild-type protein, ${ }^{88,89}$ indicating that flexible and dynamic actin turnover is important in maintaining normal morphology and function of podocytes. Transgenic mice expressing a mutant $\alpha$-actinin 4 analogous to human $\mathrm{K} 255 \mathrm{E}$ in podocytes developed proteinuria and FSGS, suggesting that this mutation is disease-causing. ${ }^{90}$ Similarly, podocytes from mice in which the two wild-type alleles were replaced with the K255E mutants (knock-in model) showed aggregation of the mutant $\alpha$-actinin 4 with $\mathrm{F}$-actin in vivo. ${ }^{89} \mathrm{In}$ vitro, this mutation causes the exposure of a normally buried actin-binding site 1, thereby increasing its actin-binding affinity, abolishes $\mathrm{Ca}^{2+}$-medicated decrease of the actin-binding affinity normally observed in the wild type, and forms abnormally large F-actin/ $\alpha$-actinin- 4 aggregates. ${ }^{89}$ Mutations of $\alpha$-actinin 4 have been also reported in sporadic cases of FSGS. ${ }^{91,92}$ However, cellular localization of the mutated proteins and actin-binding assays suggest that these mutations are probably not disease-causing. ${ }^{88}$ Finally, $\alpha$-actinin-4 knockout mice showed severe glomerular disease. The fact that both gene deletion and gain-of-function mutations can lead to proteinuria and FSGS suggests that delicate regulations of the actin cytoskeleton by $\alpha$-actinin- 4 may be important for the integrity of podocytes. ${ }^{84}$

\section{Transient receptor potential canonical 6 channel}

Transient receptor potential canonical 6 (TRPC6) belongs to the family of transient receptor potential canonical channels that consists of TRPC1-7. It is a cation channel involved in the regulation of $\mathrm{Ca}^{2+}$ influx. ${ }^{93}$ In podocytes, TRPC1, 2, 5, and 6 are expressed. ${ }^{93}$ Since disrupted $\mathrm{Ca}^{2+}$ signaling and homeostasis were postulated to be early insults in podocyte injury, ${ }^{94}$ it is not surprising that TRPC channels play a role in podocyte injury and proteinuria. The role of TRPC6 in proteinuria was indeed confirmed when mutations of TRPC6 were found to cause familial FSGS. ${ }^{93,95,96}$ In podocytes, TRPC6 is localized at the slit diaphragm with nephrin, podocin, and CD2AP. ${ }^{93}$ The P112Q mutant of TRPC6 showed an increased calcium entry to the cells, ${ }^{97}$ which is likely to trigger the chain of calcium-induced signaling events, including cell contraction. ${ }^{5}$ In addition, activation of TRPC6 by angiotensin II was shown to activate the small guanosine diphosphatase (GTPase) RhoA in podocytes. ${ }^{98}$ Since RhoA is a well-established modulator of the actin cytoskeleton, mutant TRPC6 is likely to impact on the cytoskeleton via RhoA. Of interest, activation of RhoA in podocytes in mice was shown to induce foot-process effacement and proteinuria, ${ }^{99,100}$ supporting the idea that the TRPC6-RhoA pathway may cause podocyte injury and proteinuria. Conversely, TRPC6-null mice were significantly 
protected from angiotensin II-induced proteinuria, ${ }^{84}$ also supporting the deleterious impact of TRPC6 on podocyte health. An increased calcium influx is also seen in two other missense mutations (R895C and E897K), but is absent in other mutations (N143S, S270T, and K874X).$^{93}$ Nevertheless, it is believed that these mutations are disease-causing because of their nature (substitutions in highly conserved residues), their co-segregation with the disease phenotype, and their absence in control individuals. ${ }^{93}$ In the latter three mutants, altered interaction with other slit-diaphragm proteins or altered protein turnover may be the cause of the disease. ${ }^{93} \mathrm{~A}$ recent study reported novel TRPC6 mutations (N125S, L780P) in sporadic FSGS patients; however, the same mutations were found in asymptomatic relatives as well. ${ }^{96}$ No biochemical studies (only in silico scoring matrix, which was developed to evaluate the pathogenicity of amino acid substitutions by using the biophysical and biochemical differences between wild-type and mutant amino acid) have been conducted to characterize these two mutants, thus it is possible that the mutants are not disease-causing. Alternately, these mutations may have incomplete penetrance, and "multihits" on several proteins involved in the glomerular permeability might need to be abnormal to present a distinct phenotype. ${ }^{96}$ Finally, there is a hypothesis that TRPC6 is a sensor of mechanically and osmotically induced membrane stretch, ${ }^{71}$ as discussed in the section on podocin. This hypothesis is particularly attractive, because glomerular hyperfiltration is thought to predispose to lesions of secondary FSGS. ${ }^{90}$

\section{Phospholipase C $\varepsilon$ I}

Phospholipase C (PLC) $\varepsilon 1$ belongs to the phospholipase C family, which is necessary for cell growth and differentiation. ${ }^{101}$ PLC 1 is activated by binding of a ligand to its receptor and converts phosphatidylinositol-4,5 bisphosphate into inositol 1,4,5-triphosphate $\left(\mathrm{IP}_{3}\right)$ and diaclyglycerol. ${ }^{101} \mathrm{IP}_{3}$ releases $\mathrm{Ca}^{2+}$ from the endoplasmic reticulum. The concentration of $\mathrm{Ca}^{2+}$ in the cytoplasm regulates actin polymerization. ${ }^{102}$ In the kidney, PLCE1 expression is found in the podocyte cell body and foot processes. ${ }^{103}$ PLCE1 appears at the S-shaped stage of glomerular development and is highly expressed during the early capillary loop stage. ${ }^{103}$ PLCE1 interacts with GTPase-activating protein 1 (IQGAP1), which is found at the basal aspect of the developing podocytes and interacts with nephrin. ${ }^{65}$ PLCE1 mutations were found in patients with familial congenital diffuse mesangial sclerosis (DMS). ${ }^{103}$ A study in patients with isolated (nonsyndromic) DMS revealed that PLC $\varepsilon 1$ truncating mutations $(28.6 \%)$ are more frequently observed than mutations of WT1 $(8.5 \%)$ or
LAMB2 (0\%), two genes known to cause isolated DMS. ${ }^{104}$ PLCE1 mutations were also found in $7.7 \%(6 / 78)$ of patients with familial FSGS. ${ }^{105}$

\section{Inverted formin 2}

Inverted formin (INF) 2 is a member of the formin family of actin-regulating proteins. ${ }^{106}$ Mutations of INF2 were found in 28 of 78 patients with autosomal dominant FSGS. ${ }^{107}$ FSGS due to mutations of INF2 has a later onset of disease (adolescence) compared to FSGS due to nephrin and podocin mutations. ${ }^{107}$ FSGS-associated mutants of INF2 induce distinct patterns of actin polymerization in cultured podocytes compared with wild-type INF2 ${ }^{106}$ INF2 was shown to interact with mammalian diaphanous-related formins (mDia), known downstream targets of RhoA. ${ }^{108}$ While INF2 normally inhibits Rho/mDia-mediated actin polymerization, FSGSassociated mutants of INF2 disrupt INF2/mDia interaction, altering $\mathrm{mDia}$ regulation, thereby leading to disturbed actin dynamics. ${ }^{108}$

\section{Myosin IE}

Myosins are molecular motors that translocate cargo proteins along actin filaments in an adenosine triphosphatedependent manner. ${ }^{109}$ Members of the myosin superfamily include at least 24 myosin classes. ${ }^{109}$ Myosin $1 \mathrm{E}$ is one of the class I myosins that consist of a single motor domain, a neck domain that binds one or more calmodulin light chains, and a cargo-binding tail domain. ${ }^{110}$ Myosin $1 \mathrm{E}$ was shown to be expressed in podocytes and myosin 1e-knockout mice exhibit proteinuria, impairment of renal function, foot-process effacement, and GBM thickening. ${ }^{111}$ Myosin $1 \mathrm{E}$ binds to dynamin via its tail domain and also interacts with actin via its head domain. ${ }^{112}$ Dominant negative dynamin causes actin reorganization and morphological changes in podocytes. ${ }^{12}$ Thus, myosin 1E may modulate podocyte actin cytoskeleton via dynamin or by directly interacting with actin. ${ }^{111}$ Myosin $1 \mathrm{E}$ mutations were found to cause autosomal recessive FSGS in childhood. ${ }^{113}$

\section{ARHGAP24}

The Rho family of small GTPases (which includes RhoA, Rac1, and Cdc42) are known to be important regulators of the actin cytoskeleton. ${ }^{114}$ Guanine nucleotide exchange factor and GAP are responsible for activating and deactivating the Rho GTPases, respectively. ${ }^{115}$ Please refer to Figure 2 for more details about Rho signaling to the actin cytoskeleton. A recent study has shown that mutations in Arhgap24 (a GAP for Rac1) were associated with cases of familial FSGS, ren- 


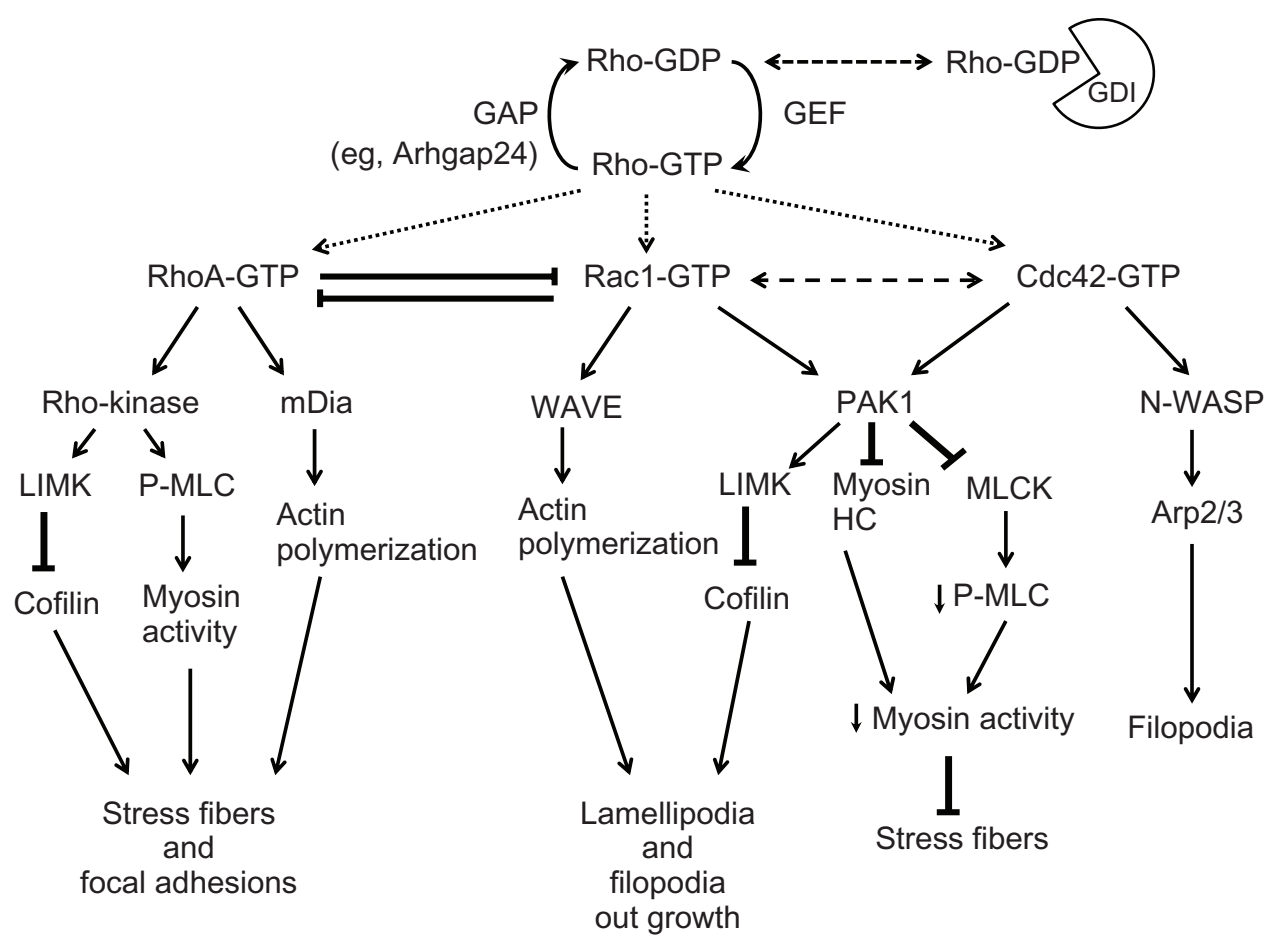

Figure 2 Signaling from Rho guanosine diphosphatases to the cytoskeleton.

Abbreviations: LIM, acronym of the three gene products Lin-I I, IsI-I, and Mec-3; LIMK, LIM kinase; P-MLC, phosphorylated myosin II light chain; PAK, P2 I-activated kinase; MLCK, myosin light chain kinase; Arp2/3, actin-related protein 2/3; WASP, Wiskott-Aldrich syndrome protein; WAVE, WASP-family verprolin-homologous protein.

dering $A R H G A P 24$ a potential candidate gene to explain a subset of inherited FSGS. ${ }^{116}$ At least one mutation was loss of function, suggesting that increased activity of Rac1 is likely to contribute to the pathogenesis. ${ }^{116}$

\section{HIV-associated nephropathy}

Patients with HIVAN most commonly present with nephrotic syndrome and collapsing FSGS on renal biopsy. ${ }^{42,117}$ However, with the advent of the highly active antiretroviral therapy, the incidence of the typical collapsing type appears to be decreasing. ${ }^{118}$ While the precise pathophysiology of HIVAN is not completely understood, it was shown that HIV could infect glomerular cells, including podocytes. ${ }^{119}$ In vitro, an HIV accessory protein, Nef, induces podocyte dedifferentiation and proliferation. ${ }^{120}$ In vivo, podocyte-specific expression of Nef and another viral protein, Vpr, induced glomerulosclerosis in mice. ${ }^{121}$ Of interest, Nef was shown to activate a small GTPase, Rac1, leading to lamellipodia formation in podocytes. ${ }^{122}$ Rac1 activation is generally associated with a migratory phenotype of the cells, ${ }^{123}$ which is believed to contribute to foot-process effacement and proteinuria. ${ }^{7,124}$ In addition, Rac1 may contribute to proteinuria via modulation of the mineral corticoid receptor. ${ }^{125}$ Thus, HIV viral proteins are likely to cause podocyte phenotypic changes via multiple pathways, contributing to proteinuria.

\section{Membranous nephropathy}

$\mathrm{MN}$ is one of the most common causes of nephrotic syndrome in adults, constituting up to one-third of biopsy diagnoses in some countries. ${ }^{126-128} \mathrm{MN}$ is divided into two main groups: primary ("idiopathic") and secondary forms. Secondary MN is associated with hepatitis B infection, systemic lupus erythematosus, thyroiditis, malignancies, and the use of drugs such as penicillamine and nonsteroidal anti-inflammatory drugs. ${ }^{127,129,130} \mathrm{MN}$ is characterized by the development of immune complexes (containing mainly immunoglobulins and complement members such as $\mathrm{C} 3$ and $\mathrm{C} 5 \mathrm{~b}-9$ ) in the subepithelial space leading to podocyte damage, causing increased production of extracellular matrix proteins and rendering the GBM thick. ${ }^{131}$ Neutral endopeptidase expressed in podocytes in babies born to mothers deficient in this enzyme was shown to be responsible in several cases of neonatal MN. ${ }^{132}$ More recently, Beck and colleagues reported that antibodies against the M-type phospholipase $\mathrm{A}_{2}$ receptor $\left(\mathrm{PLA}_{2} \mathrm{R}\right)$ were found in $80 \%$ of patients with idiopathic $\mathrm{MN} .{ }^{133}$ This breakthrough discovery established that the $\mathrm{PLA}_{2} \mathrm{R}$ expressed on the cell surface of podocytes was a common antigen causing MN. The rat model of MN (Heymann nephritis) closely mimics the pathology of human $\mathrm{MN}$ and has been used extensively to study the mechanisms of podocyte injury. In this model, sublethal complement activation was shown to activate multiple 
intracellular signaling pathways. ${ }^{129,134}$ Of particular interest, sublytic C5b-9 activated RhoA in cultured podocytes, causing the loss of cellular processes. ${ }^{135}$ In addition, nephrin redistribution and its dissociation from actin were demonstrated preceding the onset of proteinuria in Heymann nephritis. ${ }^{136,137}$ Collectively, the results suggest that complement modulates the actin cytoskeleton of podocytes via Rho-GTPases and/or by affecting nephrin-mediated signaling pathways.

\section{Hypertensive nephrosclerosis}

Hypertensive nephrosclerosis is the second-leading cause of end-stage renal disease and is particularly important in the black population. ${ }^{138}$ Histologically, the disease is characterized by a series of vascular injuries, all of which can also be detected in obesity and aging kidney. ${ }^{139,140}$ Factors contributing to the progression of the disease include arterial stiffening accompanied by an increased pressure at the afferent arteriole, ${ }^{141}$ loss of autoregulation of renal blood flow with hypertrophic and FSGS features, ${ }^{142}$ and chronic ischemia in tubulointerstitium. ${ }^{143}$ Moreover, it was shown that hypertension-associated end-stage renal disease in African-Americans is substantially related to $M Y H 9$ and/or APOL1 gene polymorphisms, ${ }^{144-149}$ raising the possibility of a genetic cause. Although the precise mechanisms of the disease remain to be elucidated, the mechanosensitive properties of the podocyte in response to glomerular capillary pressure could be an attractive candidate. It was shown that mechanical stress induced reorganization of the actin cytoskeleton, manifested in disappearance of transversal stress fibers and appearance of radial stress fibers connected to an actin-rich center. ${ }^{12}$ Thus, similar to mesangial cells, the podocyte actin cytoskeleton is likely to be adversely affected by glomerular hypertension. In addition, genetic factors may contribute to the susceptibility of podocytes to mechanical stress. Since MYH9 encodes a nonmuscle myosin heavy chain 9, MYH9 polymorphism could be an attractive candidate for such modulation.

\section{Diabetic nephropathy}

Diabetic nephropathy is the leading cause of end-stage renal disease in developed countries. ${ }^{150}$ The major pathological findings are mesangial expansion, GBM thickening, and glomerulosclerosis. ${ }^{151}$ Although almost all the cells in the kidney are known to be affected by diabetes mellitus, in this review we limit our discussion to podocytes. Glomerular mesangial cells have long been considered the main player in the pathogenesis of diabetic glomerulopathy, but recent evidence suggests that podocytes also play an important role in an early phase of diabetic nephropathy. ${ }^{152}$ Renal biopsies from Pima Indians with type 2 diabetes showed a reduction in the number of podocytes per glomerulus. ${ }^{153}$ In another cross-sectional study, a significant negative correlation was found between proteinuria and podocyte number. ${ }^{154}$ Several studies showed a decrease in nephrin protein expression in podocytes at an early stage of diabetic nephropathy, compared to nondiabetic controls. ${ }^{155,156}$ Thus, nephrin-mediated cytoskeletal regulation is likely to be dysregulated at an early stage of diabetic nephropathy, and as the disease progresses, podocyte death and podocytopenia may lead to heavy proteinuria and progressive loss of kidney function.

\section{Future direction of podocyte biology}

Starting with the discovery of nephrin in 1998, progress in podocyte biology during the last 14 years has been remarkable. Positional cloning in congenital nephrotic syndrome and familial FSGS has identified a number of important players in the normal morphology and function of podocytes. The identification of these players firmly established the actin cytoskeleton at the center of podocyte physiology and pathology. These so-called podocyte proteins (consisting of some proteins exclusively expressed in podocytes, such as nephrin and podocin, as well as some other proteins that could be detected in other cells, but play an important role in the normal physiology of podocytes) could be considered potential therapeutic targets. For example, since gain-of-function mutations of TRPC6 are detrimental to podocyte health, pharmacological inhibition of this cation channel could be beneficial in preserving the integrity of podocytes.

We also need to integrate these podocyte proteins into the understanding of nonhereditary forms of glomerular disease, including primary and secondary diseases. A number of investigations identified mutations/polymorphism in the podocyte protein genes in sporadic cases of FSGS. However, if the mutation/polymorphism is different from those identified in a hereditary disease, a causal relationship is not necessarily evident. While genetic screening of the podocyte protein genes will likely be utilized more broadly in clinical practice in the future, the significance of each variant needs to be validated. Ongoing investigations on $M Y H 9$ and $A P O L 1$ polymorphism as a risk factor to develop end-stage renal disease will likely shed light on the genetic modifiers of secondary glomerular diseases such as hypertensive nephrosclerosis.

Another approach could be to try to find "common pathways" for proteinuric glomerular diseases, in which podocyte 


\section{A Integrin signaling players necessary for normal podocyte function}

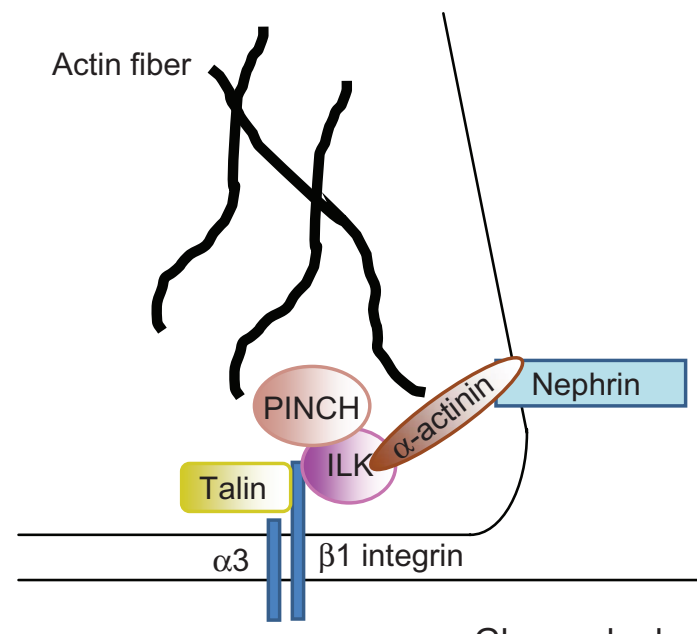

\section{B Integrin signaling mediators of podocyte injury}

Glomerular basement membrane

Figure 3 Integrin-signaling proteins in podocyte.

Notes: (A) Because podocyte-specific knockout mice of ILK, PINCH, and Talin all demonstrate proteinuria and focal segmental glomerulosclerosis, these studies show that ILK, PINCH, and Talin are integrin-signaling players necessary for normal podocyte function. (B) On the other hand, ILK is upregulated and FAK is activated in proteinuric models and diseases, and their gene deletion/inhibition was shown to be protective against podocyte injury and proteinuria, making ILK and FAK important integrin-signaling mediators of podocyte injury.

Abbreviations: ILK, integrin-linked kinase; PINCH, particularly interesting new Cys-His protein; FAK, focal adhesion kinase.

foot processes are effaced. If we find the signaling pathways that lead to foot-process effacement regardless of the initial injuries, more targeted therapeutic interventions could be devised. The Rho family of small GTPases (Figure 2) and the integrin-focal adhesion kinase (FAK) pathway ${ }^{157}$ could be promising candidates. Podocyte-specific knockout mice of several integrin-signaling proteins, such as integrin-linked kinase (ILK), particularly interesting new Cys-His protein, and talin show progressive FSGS and renal failure. ${ }^{158-161}$ On the other hand, overexpression of ILK in podocytes was found in several proteinuric models and human diseases, and an inhibitor of ILK-reduced proteinuria in Adriamycininduced proteinuria in mice. ${ }^{162}$ Similarly, podocyte-specific FAK knockout or an FAK inhibitor was protective in mice against proteinuria and foot-process effacement induced by podocyte insults (Figure 3). ${ }^{163}$ Thus, integrin/FAK pathways appear to have important roles in normal podocyte physiology and pathology. In the meantime, the quest for humoral permeability factor(s) for minimal change disease and idiopathic FSGS needs to continue, including the validation of already-discovered molecules in broader patient populations. Rapidly advancing technologies in proteomics may facilitate these endeavors.

Another potential area of investigations is the cross talk between glomerular cells. Podocytes, endothelial cells, and mesangial cells are interdependent: alterations in one cell type will result in obligatory changes in other cell types. Cross talk between endothelial cells and podocytes is already recognized, involving VEGF. ${ }^{23}$ Mutations in podocytespecific genes observed in several kidney disorders lead to mesangial proliferation (mutations in the NPHS1 gene can show mild to moderate mesangial cell proliferation; ${ }^{164}$ reduced GLEPP1 expression correlates with mesangial proliferation ${ }^{165}$ ), and the other way around, by which mesangial injury can lead to podocyte foot-process effacement. Interactions between different glomerular cell types may well be far more widespread and important than presently recognized.

Other nonmammalian systems that share similarities with mammalian systems could be utilized to understand further the importance of actin cytoskeleton in normal physiology of the cell. As an example, depletion of pat-3 ( $\beta$-integrin) or pat-4 (ILK) both lead to disruption of the actin cytoskeleton of the $C$. elegans gonad cell, resulting in an ovulation defect. ${ }^{166-168}$ In addition, mutation in nek8 gene in zebrafish disorganizes the actin cytoskeletal architecture, resulting in the formation of pronephric cysts. ${ }^{169}$ These could be used as model systems to interrogate the signaling pathways of the molecules involved in podocyte physiopathology. 


\section{Conclusion}

We have discussed the pathogenesis of common glomerular diseases, with particular interest in the role of the cytoskeleton in glomerular podocytes. While there has been robust progress in the field over the last decade, there are many remaining gaps. Filling these gaps will likely lead to more mechanism-oriented and targeted therapeutics rather than the general immunosuppressive and nonspecific treatments currently employed to treat proteinuric glomerular diseases.

\section{Acknowledgments}

We apologize to those authors whose excellent works could not be cited because of space limitations. The work of Tomoko Takano's laboratory was funded by grants from the Canadian Institute of Health Research (MOP-53335 and 97759) and the Kidney Foundation of Canada. Takanori Kumagai holds a fellowship from the Sumitomo Life Social Welfare Services Foundation.

\section{Disclosure}

The authors report no conflicts of interest in this work.

\section{References}

1. Mundel P, Kriz W. Structure and function of podocytes: an update. Anat Embryol (Berl). 1995;192(5):385-397.

2. Faul C, Asanuma K, Yanagida-Asanuma E, Kim K, Mundel P. Actin up: regulation of podocyte structure and function by components of the actin cytoskeleton. Trends Cell Biol. 2007;17(9):428-437.

3. Jefferson JA, Alpers CE, Shankland SJ. Podocyte biology for the bedside. Am J Kidney Dis. 2011;58(5):835-845.

4. Asanuma K, Mundel P. The role of podocytes in glomerular pathobiology. Clin Exp Nephrol. 2003;7(4):255-259.

5. Greka A, Mundel P. Cell biology and pathology of podocytes. Annu Rev Physiol. 2012;74:299-323.

6. Saxen L, Sariola H. Early organogenesis of the kidney. Pediatr Nephrol. 1987;1(3):385-392.

7. Welsh GI, Saleem MA. The podocyte cytoskeleton-key to a functioning glomerulus in health and disease. Nat Rev Nephrol. 2012;8(1):14-21.

8. Saleem MA, Zavadil J, Bailly M, et al. The molecular and functional phenotype of glomerular podocytes reveals key features of contractile smooth muscle cells. Am J Physiol Renal Physiol. 2008;295(4):F959-F970.

9. Reiser J, Kriz W, Kretzler M, Mundel P. The glomerular slit diaphragm is a modified adherens junction. J Am Soc Nephrol. 2000;11(1):1-8.

10. Endlich N, Endlich K. Stretch, tension and adhesion - adaptive mechanisms of the actin cytoskeleton in podocytes. Eur J Cell Biol. 2006;85(3-4):229-234.

11. Friedrich C, Endlich N, Kriz W, Endlich K. Podocytes are sensitive to fluid shear stress in vitro. Am J Physiol Renal Physiol. 2006;291(4): F856-F865.

12. Endlich N, Kress KR, Reiser J, et al. Podocytes respond to mechanical stress in vitro. J Am Soc Nephrol. 2001;12(3):413-422.

13. Neal CR, Muston PR, Njegovan D, et al. Glomerular filtration into the subpodocyte space is highly restricted under physiological perfusion conditions. Am J Physiol Renal Physiol. 2007;293(6):F1787-F1798.

14. Salmon AH, Toma I, Sipos A, et al. Evidence for restriction of fluid and solute movement across the glomerular capillary wall by the subpodocyte space. Am J Physiol Renal Physiol. 2007;293(6):F1777-F1786.
15. Peti-Peterdi J, Sipos A. A high-powered view of the filtration barrier. J Am Soc Nephrol. 2010;21(11):1835-1841.

16. Lewis EJ, Schwartz MM, Pauli BU, Sharon Z. Endocytosis: a property of the glomerular visceral epithelial cell. Nephron. 1978;22(1-3):91-96.

17. Eyre J, Ioannou K, Grubb BD, et al. Statin-sensitive endocytosis of albumin by glomerular podocytes. Am J Physiol Renal Physiol. 2007;292(2):F674-F681.

18. Akilesh S, Huber TB, Wu H, et al. Podocytes use FcRn to clear IgG from the glomerular basement membrane. Proc Natl Acad Sci USA. 2008;105(3):967-972.

19. Abrahamson DR, Hudson BG, Stroganova L, Borza DB, St John PL. Cellular origins of type IV collagen networks in developing glomeruli. J Am Soc Nephrol. 2009;20(7):1471-1479.

20. Miner JH. Developmental biology of glomerular basement membrane components. Curr Opin Nephrol Hypertens. 1998;7(1):13-19.

21. St John PL, Abrahamson DR. Glomerular endothelial cells and podocytes jointly synthesize laminin-1 and -11 chains. Kidney Int. 2001;60(3):1037-1046.

22. Schlondorff D, Banas B. The mesangial cell revisited: no cell is an island. J Am Soc Nephrol. 2009;20(6):1179-1187.

23. Eremina V, Cui S, Gerber H, et al. Vascular endothelial growth factor A signaling in the podocyte-endothelial compartment is required for mesangial cell migration and survival. JAm Soc Nephrol. 2006;17(3): 724-735.

24. Banas B, Wornle M, Berger T, et al. Roles of SLC/CCL21 and CCR7 in human kidney for mesangial proliferation, migration, apoptosis, and tissue homeostasis. J Immunol. 2002;168(9):4301-4307.

25. Ding M, Cui S, Li C, et al. Loss of the tumor suppressor Vhlh leads to upregulation of Cxcr4 and rapidly progressive glomerulonephritis in mice. Nat Med. 2006;12(9):1081-1087.

26. Banas MC, Banas B, Hudkins KL, et al. TLR4 links podocytes with the innate immune system to mediate glomerular injury. J Am Soc Nephrol. 2008;19(4):704-713.

27. Reiser J, von Gersdorff G, Loos M, et al. Induction of B7-1 in podocytes is associated with nephrotic syndrome. J Clin Invest. 2004;113(10):1390-1397

28. [No authors listed]. Nephrotic syndrome in children: prediction of histopathology from clinical and laboratory characteristics at time of diagnosis. A report of the International Study of Kidney Disease in Children. Kidney Int. 1978;13(2):159-165.

29. Ali AA, Wilson E, Moorhead JF, et al. Minimal-change glomerular nephritis. Normal kidneys in an abnormal environment? Transplantation. 1994;58(7):849-852.

30. Shalhoub RJ. Pathogenesis of lipoid nephrosis: a disorder of T-cell function. Lancet. 1974;2(7880):556-560.

31. Koyama A, Fujisaki M, Kobayashi M, Igarashi M, Narita M. A glomerular permeability factor produced by human T cell hybridomas. Kidney Int. 1991;40(3):453-460.

32. Chugh SS, Clement LC, Mace C. New insights into human minimal change disease: lessons from animal models. Am J Kidney Dis. 2012;59(2):284-292.

33. Yap HK, Cheung W, Murugasu B, Sim SK, Seah CC, Jordan SC. Th1 and Th2 cytokine mRNA profiles in childhood nephrotic syndrome: evidence for increased IL-13 mRNA expression in relapse. J Am Soc Nephrol. 1999;10(3):529-537.

34. Lai KW, Wei CL, Tan LK, et al. Overexpression of interleukin-13 induces minimal-change-like nephropathy in rats. J Am Soc Nephrol. 2007;18(5):1476-1485.

35. Clement LC, Avila-Casado C, Mace C, et al. Podocyte-secreted angiopoietin-like-4 mediates proteinuria in glucocorticoid-sensitive nephrotic syndrome. Nat Med. 2011;17(1):117-122.

36. Garin EH, Mu W, Arthur JM, et al. Urinary CD 80 is elevated in minimal change disease but not in focal segmental glomerulosclerosis. Kidney Int. 2010;78(3):296-302

37. Reiser J, Mundel P. Danger signaling by glomerular podocytes defines a novel function of inducible B7-1 in the pathogenesis of nephrotic syndrome. J Am Soc Nephrol. 2004;15(9):2246-2248. 
38. Kitiyakara C, Kopp JB, Eggers P. Trends in the epidemiology of focal segmental glomerulosclerosis. Semin Nephrol. 2003;23(2):172-182.

39. D’Agati VD, Kaskel FJ, Falk RJ. Focal segmental glomerulosclerosis. N Engl J Med. 2011;365(25):2398-2411.

40. Savin VJ, Sharma R, Sharma M, et al. Circulating factor associated with increased glomerular permeability to albumin in recurrent focal segmental glomerulosclerosis. N Engl J Med. 1996;334(14):878-883.

41. Machuca E, Benoit G, Antignac C. Genetics of nephrotic syndrome: connecting molecular genetics to podocyte physiology. Hum Mol Genet 2009;18(R2):R185-R194.

42. Klotman PE. HIV-associated nephropathy. Kidney Int. 1999;56(3): 1161-1176.

43. Dubrow A, Mittman N, Ghali V, Flamenbaum W. The changing spectrum of heroin-associated nephropathy. Am J Kidney Dis. 1985;5(1):36-41.

44. Coroneos E, Petrusevska G, Varghese F, Truong LD. Focal segmental glomerulosclerosis with acute renal failure associated with alphainterferon therapy. Am J Kidney Dis. 1996;28(6):888-892.

45. Kasiske BL, Crosson JT. Renal disease in patients with massive obesity. Arch Intern Med. 1986;146(6):1105-1109.

46. Rennke HG, Klein PS. Pathogenesis and significance of nonprimary focal and segmental glomerulosclerosis. Am J Kidney Dis. 1989;13(6):443-456.

47. Pollak MR. Focal segmental glomerulosclerosis: recent advances. Curr Opin Nephrol Hypertens. 2008;17(2):138-142.

48. McCarthy ET, Sharma M, Savin VJ. Circulating permeability factors in idiopathic nephrotic syndrome and focal segmental glomerulosclerosis. Clin J Am Soc Nephrol. 2010;5(11):2115-2121.

49. Wei C, El Hindi S, Li J, et al. Circulating urokinase receptor as a cause of focal segmental glomerulosclerosis. Nat Med. 2011;17(8): 952-960.

50. Savin VJ, McCarthy ET, Sharma R, Charba D, Sharma M. Galactose binds to focal segmental glomerulosclerosis permeability factor and inhibits its activity. Transl Res. 2008;151(6):288-292.

51. Shankland SJ, Pollak MR. A suPAR circulating factor causes kidney disease. Nat Med. 2011;17(8):926-927.

52. Borza CM, SuY, Chen X, et al. Inhibition of integrin alpha2beta1 ameliorates glomerular injury. J Am Soc Nephrol. 2012;23(6):1027-1038.

53. Smith HW, Marshall CJ. Regulation of cell signalling by uPAR. Nat Rev Mol Cell Biol. 2010;11(1):23-36.

54. Maas RJ, Wetzels JF, Deegens JK. Serum-soluble urokinase receptor concentration in primary FSGS. Kidney Int. 2012;81(10): 1043-1044.

55. Trachtman H, Gipson DS, Kaskel F, et al. Regarding Maas's editorial letter on serum suPAR levels. Kidney Int. 2012;82(4):492.

56. Kestila M, Lenkkeri U, Mannikko M, et al. Positionally cloned gene for a novel glomerular protein - nephrin - is mutated in congenital nephrotic syndrome. Mol Cell. 1998;1(4):575-582.

57. Philippe A, Nevo F, Esquivel EL, et al. Nephrin mutations can cause childhood-onset steroid-resistant nephrotic syndrome. J Am Soc Nephrol. 2008;19(10):1871-1878.

58. Santin S, Garcia-Maset R, Ruiz P, et al. Nephrin mutations cause childhood- and adult-onset focal segmental glomerulosclerosis. Kidney Int. 2009;76(12):1268-1276

59. Huber TB, Benzing T. The slit diaphragm: a signaling platform to regulate podocyte function. Curr Opin Nephrol Hypertens. 2005;14(3): 211-216.

60. Jones N, Blasutig IM, Eremina V, et al. Nck adaptor proteins link nephrin to the actin cytoskeleton of kidney podocytes. Nature. 2006;440(7085):818-823.

61. Verma R, Kovari I, Soofi A, Nihalani D, Patrie K, Holzman LB. Nephrin ectodomain engagement results in Src kinase activation, nephrin phosphorylation, Nck recruitment, and actin polymerization. $J$ Clin Invest. 2006;116(5):1346-1359.

62. Li H, Zhu J, Aoudjit L, et al. Rat nephrin modulates cell morphology via the adaptor protein Nck. Biochem Biophys Res Commun. 2006;349(1): 310-316.
63. Zhu J, Sun N, Aoudjit L, et al. Nephrin mediates actin reorganization via phosphoinositide 3-kinase in podocytes. Kidney Int. 2008; 73(5):556-566.

64. George B, Verma R, Soofi AA, et al. Crk1/2-dependent signaling is necessary for podocyte foot process spreading in mouse models of glomerular disease. J Clin Invest. 2012;122(2):674-692.

65. Lehtonen S, Ryan JJ, Kudlicka K, Iino N, Zhou H, Farquhar MG. Cell junction-associated proteins IQGAP1, MAGI-2, CASK, spectrins, and alpha-actinin are components of the nephrin multiprotein complex. Proc Natl Acad Sci U S A. 2005;102(28):9814-9819.

66. Hirabayashi S, Mori H, Kansaku A, et al. MAGI-1 is a component of the glomerular slit diaphragm that is tightly associated with nephrin. Lab Invest. 2005;85(12):1528-1543.

67. Patrie KM, Drescher AJ, Welihinda A, Mundel P, Margolis B. Interaction of two actin-binding proteins, synaptopodin and alphaactinin-4, with the tight junction protein MAGI-1. J Biol Chem. 2002;277(33):30183-30190

68. Schwarz K, Simons M, Reiser J, et al. Podocin, a raft-associated component of the glomerular slit diaphragm, interacts with CD2AP and nephrin. J Clin Invest. 2001;108(11):1621-1629.

69. Goodman MB, Ernstrom GG, Chelur DS, O'Hagan R, Yao CA, Chalfie M. MEC-2 regulates C. elegans DEG/ENaC channels needed for mechanosensation. Nature. 2002;415(6875):1039-1042.

70. Huber TB, Schermer B, Muller RU, et al. Podocin and MEC-2 bind cholesterol to regulate the activity of associated ion channels. Proc Natl Acad Sci U S A. 2006;103(46):17079-17086.

71. Spassova MA, Hewavitharana T, Xu W, Soboloff J, Gill DL. A common mechanism underlies stretch activation and receptor activation of TRPC6 channels. Proc Natl Acad Sci U S A. 2006;103(44): 16586-16591.

72. Huber TB, Schermer B, Benzing T. Podocin organizes ion channellipid supercomplexes: implications for mechanosensation at the slit diaphragm. Nephron Exp Nephrol. 2007;106(2):e27-e31.

73. Moller CC, Flesche J, Reiser J. Sensitizing the slit diaphragm with TRPC6 ion channels. J Am Soc Nephrol. 2009;20(5):950-953.

74. Roselli S, Heidet L, Sich M, et al. Early glomerular filtration defect and severe renal disease in podocin-deficient mice. Mol Cell Biol. 2004;24(2):550-560.

75. Boute N, Gribouval O, Roselli S, et al. NPHS2, encoding the glomerular protein podocin, is mutated in autosomal recessive steroid-resistant nephrotic syndrome. Nat Genet. 2000;24(4):349-354.

76. Tsukaguchi H, Sudhakar A, Le TC, et al. NPHS2 mutations in late-onset focal segmental glomerulosclerosis: R229Q is a common diseaseassociated allele. $J$ Clin Invest. 2002;110(11):1659-1666.

77. He N, Zahirieh A, Mei Y, et al. Recessive NPHS2 (Podocin) mutations are rare in adult-onset idiopathic focal segmental glomerulosclerosis. Clin J Am Soc Nephrol. 2007;2(1):31-37.

78. Shih NY, Li J, Karpitskii V, et al. Congenital nephrotic syndrome in mice lacking CD2-associated protein. Science. 1999;286(5438): $312-315$.

79. Huber TB, Kwoh C, Wu H, et al. Bigenic mouse models of focal segmental glomerulosclerosis involving pairwise interaction of CD2AP, Fyn, and synaptopodin. J Clin Invest. 2006;116(5):1337-1345.

80. Kim JM, Wu H, Green G, et al. CD2-associated protein haploinsufficiency is linked to glomerular disease susceptibility. Science. 2003;300(5623):1298-1300.

81. Lowik MM, Groenen PJ, Pronk I, et al. Focal segmental glomerulosclerosis in a patient homozygous for a CD2AP mutation. Kidney Int. 2007;72(10):1198-1203.

82. Gigante M, Pontrelli P, Montemurno E, et al. CD2AP mutations are associated with sporadic nephrotic syndrome and focal segmental glomerulosclerosis (FSGS). Nephrol Dial Transplant. 2009;24(6): 1858-1864.

83. Yaddanapudi S, Altintas MM, Kistler AD, et al. CD2AP in mouse and human podocytes controls a proteolytic program that regulates cytoskeletal structure and cellular survival. J Clin Invest. 2011;121(10):3965-3980. 
84. Nijenhuis T, Sloan AJ, Hoenderop JG, et al. Angiotensin II contributes to podocyte injury by increasing TRPC6 expression via an NFATmediated positive feedback signaling pathway. Am J Pathol. 2011; 179(4):1719-1732.

85. Kos CH, Le TC, Sinha S, et al. Mice deficient in alpha-actinin-4 have severe glomerular disease. J Clin Invest. 2003;111(11):1683-1690.

86. Otey CA, Pavalko FM, Burridge K. An interaction between alpha-actinin and the beta 1 integrin subunit in vitro. $J$ Cell Biol. 1990;111(2):721-729.

87. Kaplan JM, Kim SH, North KN, et al. Mutations in ACTN4, encoding alpha-actinin-4, cause familial focal segmental glomerulosclerosis. Nat Genet. 2000;24(3):251-256.

88. Weins A, Kenlan P, Herbert S, et al. Mutational and biological analysis of alpha-actinin-4 in focal segmental glomerulosclerosis. J Am Soc Nephrol. 2005;16(12):3694-3701.

89. Weins A, Schlondorff JS, Nakamura F, et al. Disease-associated mutant alpha-actinin-4 reveals a mechanism for regulating its F-actin-binding affinity. Proc Natl Acad Sci U S A. 2007;104(41):16080-16085.

90. Meyrier A. Mechanisms of disease: focal segmental glomerulosclerosis. Nat Clin Pract Nephrol. 2005;1(1):44-54.

91. Aucella F, De Bonis P, Gatta G, et al. Molecular analysis of NPHS2 and ACTN4 genes in a series of 33 Italian patients affected by adultonset nonfamilial focal segmental glomerulosclerosis. Nephron Clin Pract. 2005;99(2):c31-c36.

92. Dai S, Wang Z, Pan X, et al. Functional analysis of promoter mutations in the ACTN4 and SYNPO genes in focal segmental glomerulosclerosis. Nephrol Dial Transplant. 2010;25(3):824-835.

93. Reiser J, Polu KR, Moller CC, et al. TRPC6 is a glomerular slit diaphragm-associated channel required for normal renal function. Nat Genet. 2005;37(7):739-744.

94. Kerjaschki D. Polycation-induced dislocation of slit diaphragms and formation of cell junctions in rat kidney glomeruli: the effects of low temperature, divalent cations, colchicine, and cytochalasin B. Lab Invest. 1978;39(5):430-440.

95. Prakash S, Chung KW, Sinha S, et al. Autosomal dominant progressive nephropathy with deafness: linkage to a new locus on chromosome 11q24. J Am Soc Nephrol. 2003;14(7):1794-1803.

96. Santin S, Ars E, Rossetti S, et al. TRPC6 mutational analysis in a large cohort of patients with focal segmental glomerulosclerosis. Nephrol Dial Transplant. 2009;24(10):3089-3096.

97. Winn MP, Conlon PJ, Lynn KL, et al. A mutation in the TRPC6 cation channel causes familial focal segmental glomerulosclerosis. Science. 2005;308(5729):1801-1804

98. Tian D, Jacobo SM, Billing D, et al. Antagonistic regulation of actin dynamics and cell motility by TRPC 5 and TRPC6 channels. Sci Signal. 2010;3(145):ra77.

99. Zhu L, Jiang R, Aoudjit L, Jones N, Takano T. Activation of RhoA in podocytes induces focal segmental glomerulosclerosis. J Am Soc Nephrol. 2011;22(9):1621-1630.

100. Wang L, Ellis MJ, Gomez JA, et al. Mechanisms of the proteinuria induced by Rho GTPases. Kidney Int. 2012;81(11):1075-1085.

101. Wing MR, Bourdon DM, Harden TK. PLC-epsilon: a shared effector protein in Ras-, Rho-, and G alpha beta gamma-mediated signaling. Mol Interv. 2003;3(5):273-280.

102. Freichel M, Vennekens R, Olausson J, et al. Functional role of TRPC proteins in native systems: implications from knockout and knockdown studies. J Physiol. 2005;567(Pt 1):59-66.

103. Hinkes B, Wiggins RC, Gbadegesin R, et al. Positional cloning uncovers mutations in PLCE1 responsible for a nephrotic syndrome variant that may be reversible. Nat Genet. 2006;38(12):1397-1405.

104. Gbadegesin R, Hinkes BG, Hoskins BE, et al. Mutations in PLCE1 are a major cause of isolated diffuse mesangial sclerosis (IDMS). Nephrol Dial Transplant. 2008;23(4):1291-1297.

105. Boyer O, Benoit G, Gribouval O, et al. Mutational analysis of the PLCE1 gene in steroid resistant nephrotic syndrome. J Med Genet. 2010;47(7):445-452.
106. Brown EJ, Schlondorff JS, Becker DJ, et al. Mutations in the formin gene INF2 cause focal segmental glomerulosclerosis. Nat Genet. 2010;42(1):72-76.

107. Boyer O, Benoit G, Gribouval O, et al. Mutations in INF2 are a major cause of autosomal dominant focal segmental glomerulosclerosis. J Am Soc Nephrol. 2011;22(2):239-245.

108. Sun H, Schlondorff JS, Brown EJ, Higgs HN, Pollak MR. Rho activation of $\mathrm{mDia}$ formins is modulated by an interaction with inverted formin 2 (INF2). Proc Natl Acad Sci U S A. 2011;108(7): 2933-2938.

109. Foth BJ, Goedecke MC, Soldati D. New insights into myosin evolution and classification. Proc Natl Acad Sci U S A. 2006;103(10): 3681-3686.

110. Krendel M, Mooseker MS. Myosins: tails (and heads) of functional diversity. Physiology (Bethesda). 2005;20:239-251.

111. Krendel M, Kim SV, Willinger T, et al. Disruption of Myosin 1e promotes podocyte injury. J Am Soc Nephrol. 2009;20(1):86-94.

112. Sever S, Altintas MM, Nankoe SR, et al. Proteolytic processing of dynamin by cytoplasmic cathepsin $\mathrm{L}$ is a mechanism for proteinuric kidney disease. J Clin Invest. 2007;117(8):2095-2104.

113. Mele C, Iatropoulos $\mathrm{P}$, Donadelli R, et al. MYO1E mutations and childhood familial focal segmental glomerulosclerosis. NEngl J Med. 2011;365(4):295-306.

114. Hall A. Rho GTPases and the actin cytoskeleton. Science. 1998;279(5350):509-514

115. SchmidtA, HallA. Guanine nucleotide exchange factors for Rho GTPases: turning on the switch. Genes Dev. 2002;16(13):1587-1609.

116. Akilesh S, Suleiman H, Yu H, et al. Arhgap24 inactivates Rac1 in mouse podocytes, and a mutant form is associated with familial focal segmental glomerulosclerosis. J Clin Invest. 2011;121(10):4127-4137.

117. Ross MJ, Klotman PE. Recent progress in HIV-associated nephropathy. J Am Soc Nephrol. 2002;13(12):2997-3004.

118. Izzedine H, Deray G. The nephrologist in the HAART era. AIDS. 2007;21(4):409-421.

119. Bruggeman LA, Ross MD, Tanji N, et al. Renal epithelium is a previously unrecognized site of HIV-1 infection. J Am Soc Nephrol. 2000;11(11):2079-2087.

120. Sunamoto M, Husain M, He JC, Schwartz EJ, Klotman PE. Critical role for Nef in HIV-1-induced podocyte dedifferentiation. Kidney Int. 2003;64(5):1695-1701.

121. Zuo Y, Matsusaka T, Zhong J, et al. HIV-1 genes vpr and nef synergistically damage podocytes, leading to glomerulosclerosis. J Am Soc Nephrol. 2006;17(10):2832-2843.

122. Lu TC, He JC, Wang ZH, et al. HIV-1 Nef disrupts the podocyte actin cytoskeleton by interacting with diaphanous interacting protein. $J$ Biol Chem. 2008;283(13):8173-8182.

123. Burridge K, Wennerberg K. Rho and Rac take center stage. Cell. 2004;116(2):167-179.

124. Mundel P, Reiser J. Proteinuria: an enzymatic disease of the podocyte? Kidney Int. 2010;77(7):571-580.

125. Shibata S, Nagase M, Yoshida S, et al. Modification of mineralocorticoid receptor function by Rac1 GTPase: implication in proteinuric kidney disease. Nat Med. 2008;14(12):1370-1376.

126. Haas M, Meehan SM, Karrison TG, Spargo BH. Changing etiologies of unexplained adult nephrotic syndrome: a comparison of renal biopsy findings from 1976-1979 and 1995-1997. Am J Kidney Dis. 1997;30(5):621-631.

127. Braden GL, Mulhern JG, O’Shea MH, Nash SV, UcciAA Jr, Germain MJ. Changing incidence of glomerular diseases in adults. Am J Kidney Dis. 2000;35(5):878-883.

128. Rivera F, Lopez-Gomez JM, Perez-Garcia R. Clinicopathologic correlations of renal pathology in Spain. Kidney Int. 2004;66(3):898-904.

129. Cybulsky AV, Quigg RJ, Salant DJ. Experimental membranous nephropathy redux. Am J Physiol Renal Physiol. 2005;289(4):F660-F671.

130. Cybulsky AV. Membranous nephropathy. Contrib Nephrol. 2011;169:107-125. 
131. Jefferson JA, Nelson PJ, Najafian B, Shankland SJ. Podocyte disorders: Core Curriculum 2011. Am J Kidney Dis. 2011;58(4):666-677.

132. Debiec H, Guigonis V, Mougenot B, et al. Antenatal membranous glomerulonephritis due to anti-neutral endopeptidase antibodies. N Engl J Med. 2002;346(26):2053-2060.

133. Beck LH Jr, Bonegio RG, Lambeau G, et al. M-type phospholipase A2 receptor as target antigen in idiopathic membranous nephropathy. N Engl J Med. 2009;361(1):11-21.

134. Susani M, Schulze M, Exner M, Kerjaschki D. Antibodies to glycolipids activate complement and promote proteinuria in passive Heymann nephritis. Am J Pathol. 1994;144(4):807-819.

135. Zhang H, Cybulsky AV, Aoudjit L, et al. Role of Rho-GTPases in complement-mediated glomerular epithelial cell injury. Am J Physiol Renal Physiol. 2007;293(1):F148-F156.

136. Nakatsue T, Koike H, Han GD, et al. Nephrin and podocin dissociate at the onset of proteinuria in experimental membranous nephropathy. Kidney Int. 2005;67(6):2239-2253.

137. Saran AM, Yuan H, Takeuchi E, McLaughlin M, Salant DJ. Complement mediates nephrin redistribution and actin dissociation in experimental membranous nephropathy. Kidney Int. 2003;64(6):2072-2078.

138. Hill GS. Hypertensive nephrosclerosis. Curr Opin Nephrol Hypertens. 2008; 17(3):266-270.

139. Tracy RE. Age trends of renal arteriolar hyalinization explored with the aid of serial sections. Nephron Clin Pract. 2007;105(4):c171-c177.

140. Camici M, Carpi A, Cini G, Galetta F, Abraham N. Podocyte dysfunction in aging-related glomerulosclerosis. Front Biosci (Schol Ed). 2011;3:995-1006.

141. O'Rourke MF, Safar ME. Relationship between aortic stiffening and microvascular disease in brain and kidney: cause and logic of therapy. Hypertension. 2005;46(1):200-204.

142. Hill GS, Heudes D, Jacquot C, Gauthier E, Bariety J. Morphometric evidence for impairment of renal autoregulation in advanced essential hypertension. Kidney Int. 2006;69(5):823-831.

143. Fine LG, Orphanides C, Norman JT. Progressive renal disease: the chronic hypoxia hypothesis. Kidney Int Suppl. 1998;65:S74-S78.

144. Freedman BI, Hicks PJ, Bostrom MA, et al. Polymorphisms in the nonmuscle myosin heavy chain 9 gene (MYH9) are strongly associated with end-stage renal disease historically attributed to hypertension in African Americans. Kidney Int. 2009;75(7):736-745.

145. Freedman BI, Murea M. Target organ damage in African American hypertension: role of APOL1. Curr Hypertens Rep. 2012;14(1):21-28.

146. Arrondel C, Vodovar N, Knebelmann B, et al. Expression of the nonmuscle myosin heavy chain IIA in the human kidney and screening for MYH9 mutations in Epstein and Fechtner syndromes. J Am Soc Nephrol. 2002;13(1):65-74.

147. Genovese G, Friedman DJ, Ross MD, et al. Association of trypanolytic ApoL1 variants with kidney disease in African Americans. Science. 2010;329(5993):841-845.

148. Kao WH, Klag MJ, Meoni LA, et al. MYH9 is associated with nondiabetic end-stage renal disease in African Americans. Nat Genet. 2008;40(10):1185-1192.

149. Tzur S, Rosset S, Shemer R, et al. Missense mutations in the APOL1 gene are highly associated with end stage kidney disease risk previously attributed to the MYH9 gene. Hum Genet. 2010;128(3):345-350.

150. Molitch ME, DeFronzo RA, Franz MJ, et al. Nephropathy in diabetes. Diabetes Care. 2004;27 Suppl 1:S79-S83.

151. Tervaert TW, Mooyaart AL, Amann K, et al. Pathologic classification of diabetic nephropathy. J Am Soc Nephrol. 2010;21(4):556-563.

152. Ziyadeh FN, Wolf G. Pathogenesis of the podocytopathy and proteinuria in diabetic glomerulopathy. Curr Diabetes Rev. 2008;4(1):39-45.

153. Pagtalunan ME, Miller PL, Jumping-Eagle S, et al. Podocyte loss and progressive glomerular injury in type II diabetes. J Clin Invest. 1997;99(2):342-348.

154. White KE, Bilous RW. Structural alterations to the podocyte are related to proteinuria in type 2 diabetic patients. Nephrol Dial Transplant. 2004;19(6):1437-1440.
155. Koop K, Eikmans M, Baelde HJ, et al. Expression of podocyteassociated molecules in acquired human kidney diseases. $J \mathrm{Am}$ Soc Nephrol. 2003;14(8):2063-2071.

156. Benigni A, Gagliardini E, Tomasoni S, et al. Selective impairment of gene expression and assembly of nephrin in human diabetic nephropathy. Kidney Int. 2004;65(6):2193-2200.

157. Ma H, Togawa A, Soda K, et al. Inhibition of podocyte FAK protects against proteinuria and foot process effacement. J Am Soc Nephrol. 2010;21(7):1145-1156.

158. Dai C, Stolz DB, Bastacky SI, et al. Essential role of integrin-linked kinase in podocyte biology: Bridging the integrin and slit diaphragm signaling. J Am Soc Nephrol. 2006;17(8):2164-2175.

159. El-Aouni C, Herbach N, Blattner SM, et al. Podocyte-specific deletion of integrin-linked kinase results in severe glomerular basement membrane alterations and progressive glomerulosclerosis. J Am Soc Nephrol. 2006;17(5):1334-1344.

160. Hodgin JB, Liang X, Blattner SM, et al. TH-OR028: PINCH-1 and -2 are essential for podocyte adhesion, shape modulation and maintenance of glomerular filtration barrier function. Proceedings of ASN (American Society of Nephrology) Conference; November 8-13, 2011; Philadelphia, PA, USA.

161. Tian X, Zheng R, Zent R, Ishibe S. TH-OR029: Loss of talin 1 in podocytes results in severe progressive albuminuria and kidney failure. Proceedings of ASN (American Society of Nephrology) Conference; November 8-13, 2011; Philadelphia, PA, USA.

162. Kang YS, Li Y, Dai C, Kiss LP, Wu C, Liu Y. Inhibition of integrinlinked kinase blocks podocyte epithelial-mesenchymal transition and ameliorates proteinuria. Kidney Int. 2010;78(4):363-373.

163. Ma H, Togawa A, Soda K, et al. Inhibition of podocyte FAK protects against proteinuria and foot process effacement. J Am Soc Nephrol. 2010;21(7):1145-1156.

164. Garcia-Mata R, Boulter E, Burridge K. The 'invisible hand': regulation of RHO GTPases by RHOGDIs. Nat Rev Mol Cell Biol. 2011;12(8): 493-504.

165. Tian J, Wang HP, Mao YY, Jin J, Chen JH. Reduced glomerular epithelial protein 1 expression and podocyte injury in immunoglobulin A nephropathy. $J$ Int Med Res. 2007;35(3):338-345.

166. Cram EJ, Clark SG, Schwarzbauer JE. Talin loss-of-function uncovers roles in cell contractility and migration in C. elegans. $J$ Cell Sci. 2003;116(Pt 19):3871-3878.

167. Lee M, Cram EJ, Shen B, Schwarzbauer JE. Roles for beta(pat-3) integrins in development and function of Caenorhabditis elegans muscles and gonads. J Biol Chem. 2001;276(39):36404-36410.

168. Ono K, Ono S. Tropomyosin and troponin are required for ovarian contraction in the Caenorhabditis elegans reproductive system. Mol Biol Cell. 2004;15(6):2782-2793.

169. Liu S, Lu W, Obara T, et al. A defect in a novel Nek-family kinase causes cystic kidney disease in the mouse and in zebrafish. Development. 2002;129(24):5839-5846.

170. Pelletier J, Bruening W, Kashtan CE et al. Germline mutations in the Wilms' tumor suppressor gene are associated with abnormal urogenital development in Denys-Drash syndrome. Cell. 1991;67(2):437-447.

171. Pelletier J, Schalling M, Buckler AJ, Rogers A, Haber DA, Housman D. Expression of the Wilms' tumor gene WT1 in the murine urogenital system. Genes Dev. 1991;5(8):1345-1356.

172. Morello R, Zhou G, Dreyer SD et al. Regulation of glomerular basement membrane collagen expression by LMX1B contributes to renal disease in nail patella syndrome. Nat Genet. 2001;27(2):205-208.

173. Schnabel E, Anderson JM, Farquhar MG. The tight junction protein ZO-1 is concentrated along slit diaphragms of the glomerular epithelium. J Cell Biol. 1990;111(3):1255-1263.

174. Wharram BL, Goyal M, Gillespie PJ et al. Altered podocyte structure in GLEPP1 (Ptpro)-deficient mice associated with hypertension and low glomerular filtration rate. J CLin Invest. 2000;106(10):1281-1290.

175. Tian J, Wang HP, Mao YY, Jin J, Chen JH. Reduced glomerular epithelial protein 1 expression and podocyte injury in immunoglobulin A nephropathy. J Int Med Res. 2007;35(3):338-345. 


\section{Publish your work in this journal}

Cell Health and Cytoskeleton is an international, peer-reviewed open access journal focusing on all aspects of cell structure and function contributing to normal physiology and cell health and exploring the pathogenesis of cell dysfunction leading to adverse conditions and disease in the organism. The journal welcomes papers covering original research,

basic science, reviews and evaluations, guidelines, expert opinion and commentary, case reports and extended reports. The manuscript management system is completely online and includes a very quick and fair peerreview system, which is all easy to use. Visit http://www.dovepress.com/ testimonials.php to read real quotes from published authors.

Submit your manuscript here: http://www.dovepress.com/cell-health-and-cytoskeleton-journal 